\title{
Disparities in Excess Mortality Between Indigenous and Non-Indigenous Brazilians in 2020: Measuring the Effects of the COVID-19 Pandemic
}

\author{
Gustavo Hermes Soares $^{1}$ (1) $\cdot$ Lisa Jamieson ${ }^{2} \cdot$ Maria Gabriela Haye Biazevic $^{1} \cdot$ Edgard Michel-Crosato $^{1}$
}

Received: 22 July 2021 / Revised: 23 September 2021 / Accepted: 23 September 2021 / Published online: 28 September 2021

(c) W. Montague Cobb-NMA Health Institute 2021

\begin{abstract}
This study aimed to estimate the number of excess deaths among Indigenous Peoples associated with the COVID-19 pandemic in 2020 and to assess the disparities in excess mortality between Indigenous and non-Indigenous Brazilians. A time series analysis of weekly mortality data including all deaths from January 2015 to December 2020 was conducted. The number of expected deaths for 2020 was estimated using an over-dispersed Poisson model that accounts for demographic changes, temporal trends, and seasonal effects in mortality. Weekly excess deaths were calculated as the difference between the number of observed deaths and the expected deaths. Regional differences in Indigenous mortality were investigated. A significant increase in Indigenous mortality was observed from April 1 to December 31, 2020. An estimated 1149 (95\% CI 1018-1281) excess deaths was found among Indigenous Brazilians in 2020, representing a 34.8\% increase from the expected deaths for this population. The overall increase in non-Indigenous mortality was $18.1 \%$. The Indigenous population living in the Brazilian Amazon area was the earliest-affected Indigenous group, with one of the highest proportional increases in mortality. Disparities in excess mortality revealed a disproportionate burden of COVID-19 among Indigenous Brazilians compared to their non-Indigenous counterparts. Findings highlight the importance of implementing an effective emergency plan that addresses the increased vulnerability of Indigenous Peoples to COVID-19.
\end{abstract}

Keywords Indigenous population $\cdot$ Excess deaths $\cdot$ Pandemic $\cdot$ COVID-19 $\cdot$ Mortality $\cdot$ Vulnerable groups

\section{Introduction}

The emergence of the novel coronavirus (SARS-CoV-2) as a global pandemic has challenged the capacity and preparedness of health systems worldwide in managing public health crises. Despite a long tradition in community-based health strategies and previous positive experiences handling sanitary emergencies [1, 2], Brazil has reportedly had a disastrous response to the spread of the 2019 coronavirus disease (COVID-19) [3, 4]. The federal administration has been criticized by the international scientific community for downplaying the severity of COVID-19, in addition to immersing

Gustavo Hermes Soares

ghsoares@ outlook.com.br

1 University of São Paulo Dental School, Av. Prof. Lineu Prestes, 2227 - Butantã, São Paulo, SP 05508-000, Brazil

2 Australian Research Centre for Population Oral Health, The University of Adelaide, Adelaide, SA, Australia the country in scientific denialism, undermining the efforts of other entities to reduce the impact of the disease, and refusing to implement a central public health governance during the pandemic [5-7]. Up to September 2021, Brazil had accumulated over 590,000 deaths from COVID-19, only second to the toll of victims in the USA [8].

The lack of effective measures to protect vulnerable groups during the pandemic prompted the Brazilian Supreme Court to determine that the federal government implemented an emergency plan for tackling COVID-19 among the Indigenous population [9]. Indigenous Brazilians correspond to approximately $0.4 \%$ of the Brazilian population. This group is constituted by 305 different Indigenous Peoples living in all regions of the country. The Amazon area concentrates the highest Indigenous population of the country, in addition to over 100 Indigenous communities living in voluntary isolation - the greatest number of native peoples classified as isolated in the world $[10,11]$. This remarkably diverse population is consistently affected by social marginalization, structural racism, and worse sociodemographic and 
health conditions compared to their non-Indigenous counterparts [11-13]. Barriers to accessing health services and the intensification of conflicts with land-invaders exacerbate the Indigenous vulnerability to the COVID-19 pandemic [14].

Only in March 2021, 7 months after the ruling, the Ministry of Health presented a plan that was partially sanctioned by the Supreme Court [15]. Although the Indigenous population was later included as a priority group for the COVID19 vaccination, the response of the Special Secretary of Indigenous Health to the pandemic failed to recognize the Indigenous Brazilians living in urban areas, leaving approximately $36 \%$ of the Indigenous population unassisted during an unprecedented public health emergency $[11,16]$. A study revealed that Indigenous Brazilians living in urban settings have a twofold higher prevalence rate of COVID-19 compared to the non-Indigenous population [17].

The vulnerability of Indigenous Brazilians-whether living in traditional lands or urban areas-to COVID-19 is shaped by a complex interplay of broader determinants of health that include social marginalization, poor housing conditions, structural racism, and colonial legacy [16, 18]. Information collected by the Articulation of the Indigenous Peoples of Brazil (APIB), the widest movement of Indigenous Peoples from Brazil, reveals that 161 different Indigenous Peoples (53\%) from all regions of Brazil were directly affected by the pandemic in 2020 [19]. The COVID-19 constitutes a tangible threat for the survival and cultural continuity of several of these millenary Indigenous groups. For instance, there are 24 Indigenous Peoples entirely formed by up to 100 individuals to which the pandemic could result in a decimation [20]. Furthermore, the pandemic may have a profound effect on Indigenous cultures. Indigenous elders are at increased risk of death from COVID-19 due to advanced age, impacting their central role in Indigenous cultures and epistemologies as traditional knowledge keepers [16]. Other health and socioeconomic effects of the pandemic on Indigenous communities may include difficulties in accessing health services and obtaining food supplies, exacerbating a context of epidemiological vulnerability and food insecurity $[18,21]$.

In this study, we investigated the effects of the COVID-19 pandemic on Indigenous Brazilians mortality. Based on a time series analysis of mortality data from 2015 to 2019 , we compared the estimates of excess deaths for 2020 between the Indigenous and the non-Indigenous populations. Excess mortality is a measure that allows the identification of unusually high mortality rates for a specific demographic and time interval, providing important information regarding the overall impact of the pandemic across populations. The number of excess deaths is calculated as the difference between the number of observed deaths and the number of expected deaths for the same period. Previous studies adopted different approaches to estimate the excess mortality associated with the COVID-19 pandemic, including comparing the number of observed deaths with the figures reported in 2019 or with the historical average of deaths in past years [22, 23]. This study advances the scientific literature by applying a robust statistical approach that estimates the expected number of deaths for a given period while accounting for a recent demographic change in the Indigenous population from Brazil [24]. Thus, this study aimed to estimate the number of excess deaths among Indigenous Peoples associated with the COVID-19 pandemic in 2020 and to assess the disparities in excess mortality between Indigenous and non-Indigenous Brazilians.

\section{Methods}

\section{Study Design}

A time series of weekly mortality data was conducted to assess the excess of deaths among Indigenous Brazilians in 2020 .

\section{Data}

Daily mortality data were obtained from the Mortality Information System of the Brazilian Health System including all deaths reported from January 12015 to December 312020 $[25,26]$. The 2020 mortality dataset used for our analyses was last revised by the Ministry of Health on September 1, 2021.

Annual mid-year population estimates for Brazil were obtained for each year included in the analysis from the Brazilian Institute of Geography and Statistics [27]. These figures represent the total population living in the country and do not include information on Indigenous status.

The most updated information available for the Indigenous population was obtained from the 2010 Brazilian National Census, which was considered the initial population [11]. To calculate the annual population size of Indigenous Brazilians from 2015 to 2020, we defined population growth as the balance of the number of births and deaths in a given year (we did not account for migration as it has a reduced influence over population growth). The change in population size (number of live births-number of deaths) was computed for each year between 2010 and 2019. The annual number of Indigenous live births was obtained from the Brazilian Live Birth Information System and the annual number of Indigenous deaths from the Mortality Information System [25, 28]. The differences between the number of live births and deaths were added to the initial population estimates, accounting for sex and region. For instance, the size of the Indigenous population in 2020 is represented by the total Indigenous population in 2010 plus the sum of the 
population change from 2010 to 2019 . Thus, the Indigenous population in a given year can be expressed as follows:

$P(t)=P_{2010}+\sum_{i=2010}^{t-1}\left(b_{i}-d_{i}\right)$

where $P(t)$ is the population size at year $\mathrm{t} ; P_{2010}$ is the number of individuals in year 2010; $b_{i}$ is the total number of births in year $\mathrm{i} ; d_{i}$ is the total number of deaths in year $\mathrm{i}$; $i=2010$ is the first term of summation; and $t-1$ is the last term of summation. Adjustments were also made by region. The updated population size of Indigenous Brazilians from 2010 to 2020 is provided as Online Resource.

\section{Analysis}

The data analyzed included individual information on date of death, ethnicity, and country region. We considered the total number of deaths reported in the mortality system (from all causes). Ethnicity was the only variable with missing information (the proportion of deaths with no record of ethnic background ranged from $2.6 \%$ in 2019 to $4.5 \%$ in 2020). To account for missing ethnicity information, we considered an equal probability of missing ethnicity data for Indigenous and non-Indigenous Brazilians. Based on the proportion of Indigenous deaths in 2019 (the year with the most complete information available), we considered that $0.325 \%$ of the weekly deaths with missing ethnicity information were Indigenous and $99.675 \%$ were non-Indigenous. To assess the impact of the imputed information, we built an alternative scenario in which all deaths with missing ethnicity information were treated as non-Indigenous.

Weekly expected deaths were estimated using an overdispersed Poisson model accounting for population growth, temporal trends, and seasonal effects in mortality. The model considered the historical mortality data from January 2015 to December 2019 to estimate the expected number of deaths for Indigenous and Non-Indigenous Brazilians in 2020. We identified the periods of 2020 when observed deaths were above the $95 \%$ upper confidence limit of expected mortality. Excess deaths were calculated as the difference between observed deaths and expected deaths in each period. Regional differences in excess deaths of Indigenous Brazilians were also examined. The excessmort $\mathrm{R}$ package was used to model the time series. Previous studies demonstrated the validity of this approach to estimate excess mortality with both simulation and COVID-19 data [24, 29].

We also compared excess mortality with reported number of deaths from COVID-19 in both ethnic groups. Temporal trends were presented as absolute figures and per 100,000. The ratio of excess deaths to reported COVID-19 deaths was reported. Analyses were conducted using RStudio version
1.4.1106. All the data used in this study are anonymised and publicly available.

\section{Results}

The estimated Indigenous population in 2020 comprised $1,086,043$ individuals, equivalent to $0.5 \%$ of the overall Brazilian population (Online Resource). The annual population growth rate of Indigenous Brazilians from 2010 to 2020 was $2.1 \%$. The Indigenous population living in the North region presented the highest annual population growth rate (3.1\%), whereas the Indigenous Peoples from the Northeast had the lowest $(1.2 \%)$.

There were 5653 Indigenous deaths in Brazil in 2020, corresponding to $0.36 \%$ of all deaths. We found evidence of excess deaths for both Indigenous and non-Indigenous Brazilians, although the proportional increase in mortality was more pronounced among the Indigenous population (Fig. 1). The model detected a significant increase in Indigenous mortality from April 01 to December 31. The peak in excess deaths of Indigenous Brazilians occurred in June, approximately a month after the peak in non-Indigenous excess deaths. Despite the identification of a small increase in non-Indigenous mortality in February, we reported only the excess deaths among non-Indigenous Brazilians from March to December as the first confirmed COVID-19 case in the country was registered on February 26.

The estimated number of excess deaths for Indigenous Brazilians in 2020 was 1149 (95\% CI 1018-1281), representing a $34.8 \%$ increase from the expected mortality for this population (Table 1). The overall increase in non-Indigenous mortality was $18.1 \%$, with an estimated number of excess deaths of 207,765 (95\% CI 205,436-210,093). The cumulative excess deaths per 100,000 in 2020 was higher among the Indigenous population, with statistically significant differences in the period from June to November (Fig. 2).

We tested an alternative model in which all records with missing ethnicity information were considered non-Indigenous deaths. The alternative model had a substantial impact on absolute and relative indicators of Indigenous mortality, but nearly no effect on the indicators of non-Indigenous mortality. Overall, the alternative model failed to detect a statistically significant increase in Indigenous mortality between October and November. Moreover, the ratio of excess deaths to reported COVID-19 deaths was exceptionally low (0.68), which is an unlikely scenario considering the significant proportional increase in deaths detected by the model. For this reason, we refrain from further interpreting the results of the alternative model (Online Resource).

Important regional differences in Indigenous excess deaths were identified (Fig. 3). The Indigenous population living in the North region was the earliest-affected 
Fig. 1 Weekly percentage deviation from expected deaths for Indigenous and non-Indigenous Brazilians in 2020

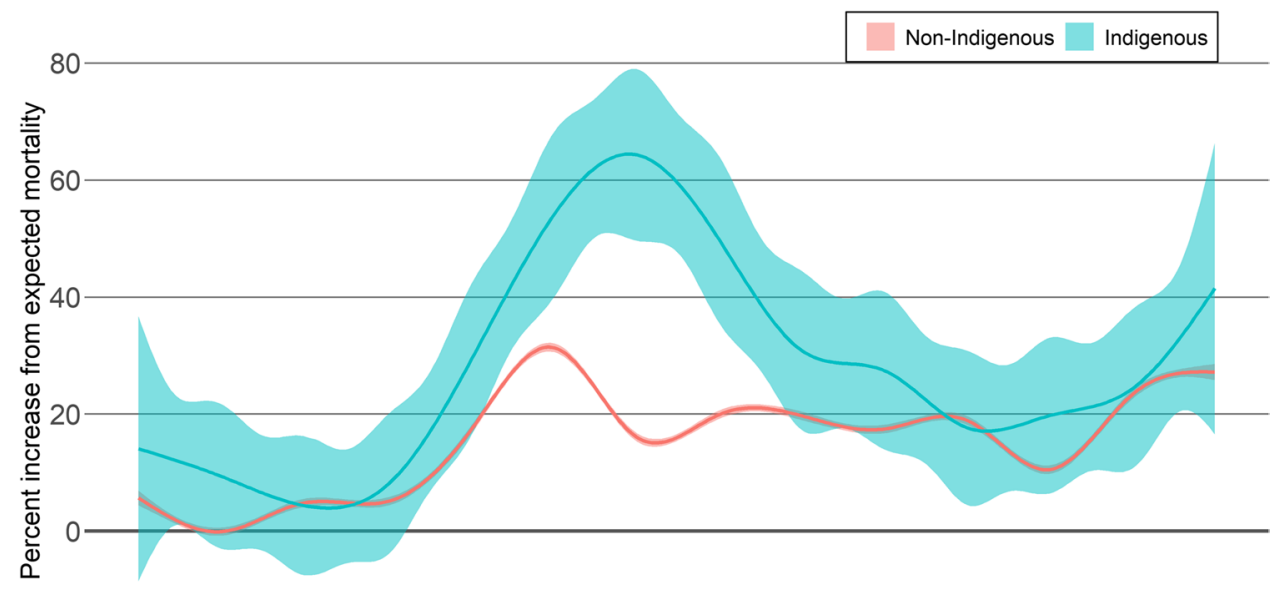

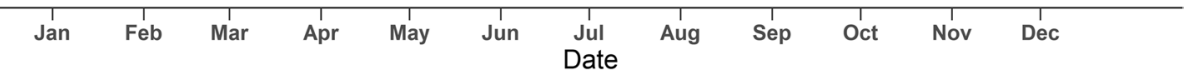

Table 1 Comparison of absolute and relative measures of excess mortality between Indigenous and non-Indigenous Brazilians in 2020

\begin{tabular}{lll}
\hline & Indigenous & Non-Indigenous \\
\hline Total deaths in 2020 & 5653 & $1,572,251$ \\
Observed deaths in the corresponding intervals & $4452^{\mathrm{a}}$ & $1,356,945^{\mathrm{b}}$ \\
Excess deaths & $1149(95 \%$ CI $1018-$ & $207,765(95 \%$ \\
& $1281)^{\mathrm{a}}$ & CI 205,436- \\
& & $210,093)^{\mathrm{b}}$ \\
Excess deaths/100,000 & 106 & 98 \\
COVID deaths & 962 & 202,081 \\
Ratio excess deaths/COVID-19 deaths & 1.19 & 1.03 \\
\hline
\end{tabular}

${ }^{\mathrm{a}}$ From April 1 to December 31

${ }^{\mathrm{b}}$ From March 1 to December 31 group during the first wave of the pandemic in Brazil in 2020. Subsequentially, the Northeast and the Center-West regions experienced significant increases in mortality, although the former observed a more discrete increment in deaths from all causes. The models did not detect statistically significant increases in mortality among the Indigenous populations living in the Southeast and the South up to December, when a strong tendency of increase in mortality was observed.

Figure 4 presents the temporal patterns of observed deaths, expected deaths, and deaths from COVID-19 among Indigenous and non-Indigenous Brazilians in 2020. Most deaths from COVID-19 overlap with the weekly excess deaths in both groups, indicating that excess deaths in 2020 were predominantly caused by the disease. Periods in which the deaths from COVID-19 exceeded the estimates of excess deaths signal a potential reduction in mortality from other causes such as unintentional injuries (including violence and accidents). Conversely, intervals in which the number of excess deaths surpassed the reported deaths from COVID-19 reveal the indirect effects of the pandemic that contributed to greater mortality.

\section{Discussion}

In this study, we compared the effects of the COVID-19 pandemic on the excess mortality between the Indigenous and non-Indigenous populations from Brazil in 2020. Based on historical mortality data from January 2015 to December 2019, we estimated the expected number of deaths for Indigenous and non-Indigenous Brazilians in the counterfactual scenario of no pandemic. The percentual increase in mortality from the estimated expected deaths was substantially higher among the Indigenous population compared to the non-Indigenous population. Important regional differences related to the magnitude and the periods with excess deaths were observed. The Indigenous population living in the Brazilian Amazon area was the earliest-affected Indigenous group, with one of the highest proportional increases 


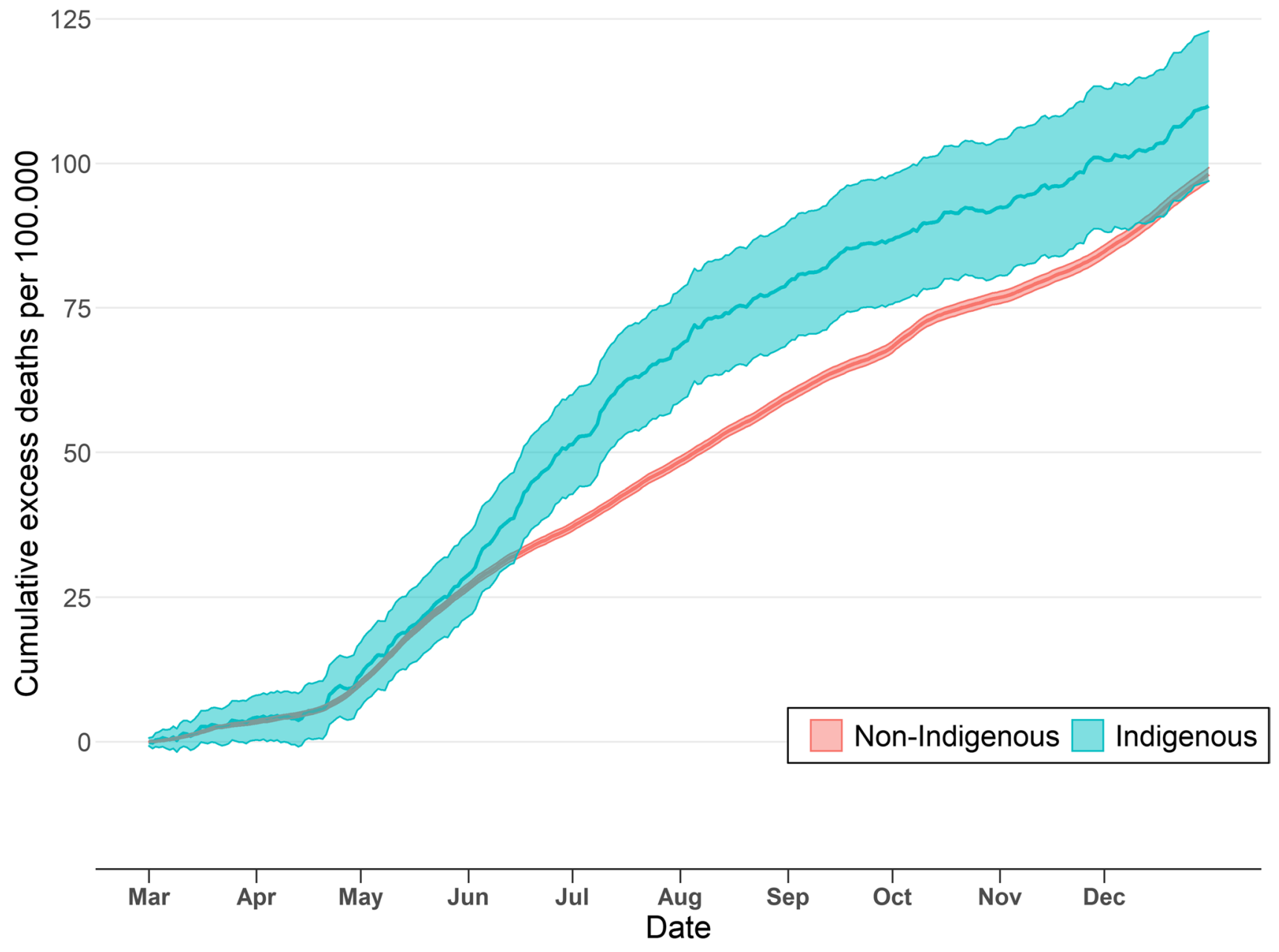

Fig. 2 Cumulative number of excess deaths per 100,000 individuals for Indigenous and non-Indigenous Brazilians in 2020

in mortality associated with the COVID-19 pandemic. The estimated number of excess deaths among the Indigenous population was greater than the reported COVID-19 deaths, whereas the number of excess deaths was slightly lower than the reported number of deaths from COVID-19 among the non-Indigenous Brazilian population.

To the best of our knowledge, this is the first study to examine the excess mortality among Indigenous Brazilians during the COVID-19 pandemic. Previous studies reported substantially higher excess deaths among the Brazilian population, although their analyses were restricted to a few large cities, deaths by natural causes, or smaller intervals of time [22, 30, 31]. Differences between our results and previous findings may also be largely influenced by the estimation procedures adopted. Other studies have not addressed factors such as data overdispersion, temporal trends, seasonal effects in mortality, and demographic changes, which could have contributed to underestimating the expected number of deaths in 2020 - and, consequently, overestimating the number of excess deaths.
In contrast with other studies, we were not able to assess the level of under-reporting of COVID-19 deaths $[32,33]$. Findings are not directly comparable due to important methodological differences between studies. For instance, Alves et al. (2021) analyzed only the excess deaths from causes that are clinically similar to COVID-19, an approach that is more appropriate for investigating the level of under-reporting in mortality associated with COVID-19 [32]. A study conducted by Fellows et al. (2021) observed an under-reporting of 14 and $103 \%$ in confirmed cases and deaths from COVID19 , respectively, among the Indigenous population living in the Brazilian Amazon [34]. In this study, we provide a comprehensive analysis of the impacts of the pandemic on Indigenous and non-Indigenous mortality, including data on deaths from all causes. Additionally, we demonstrated that even low levels of missing ethnicity information on death records may underestimate the magnitude of disparities in mortality between Indigenous and nonIndigenous populations. Labgold et al. (2020) observed 

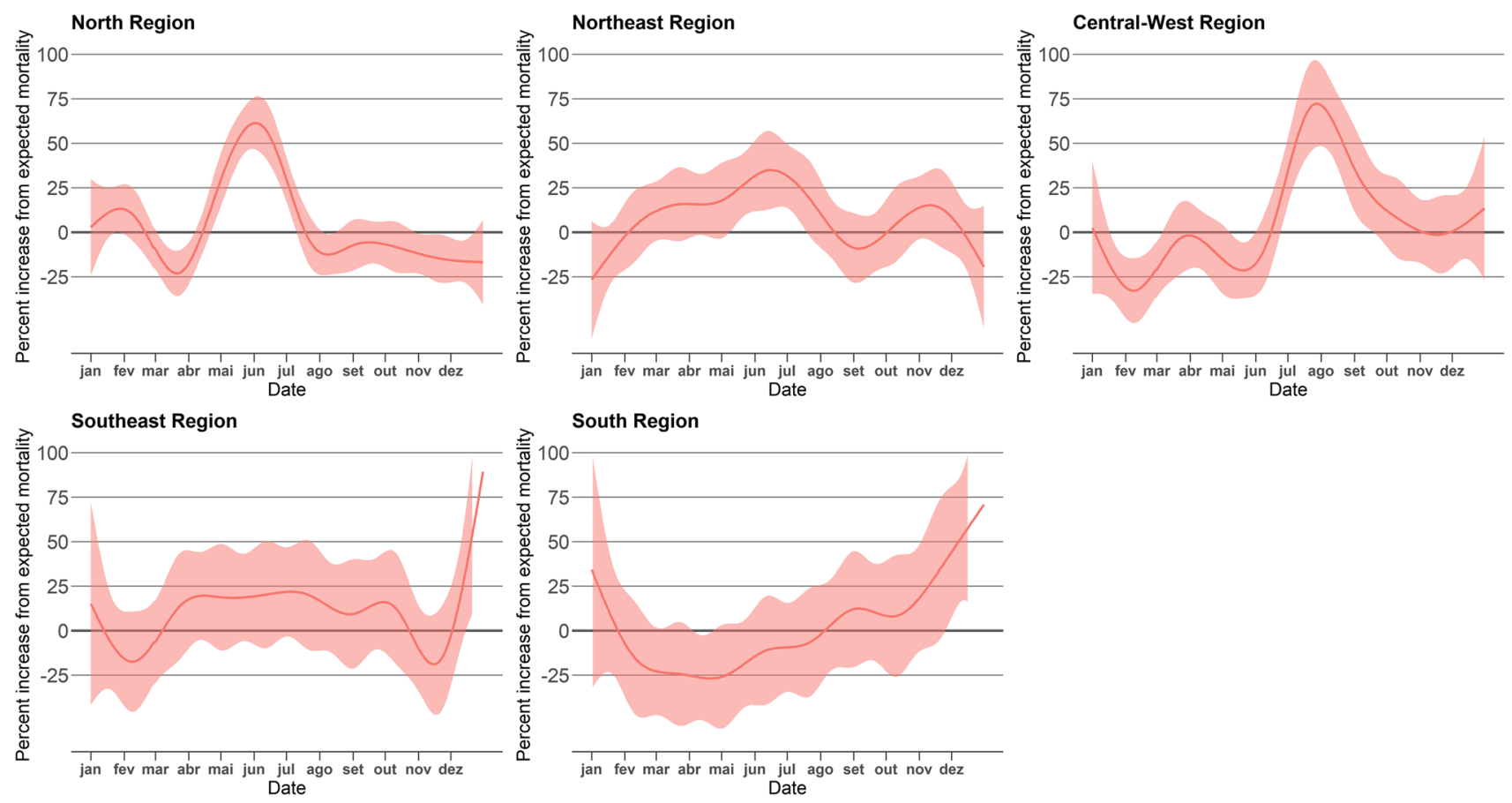

Fig. 3 Weekly percentage deviation from expected deaths for Indigenous Brazilians in 2020 according to region
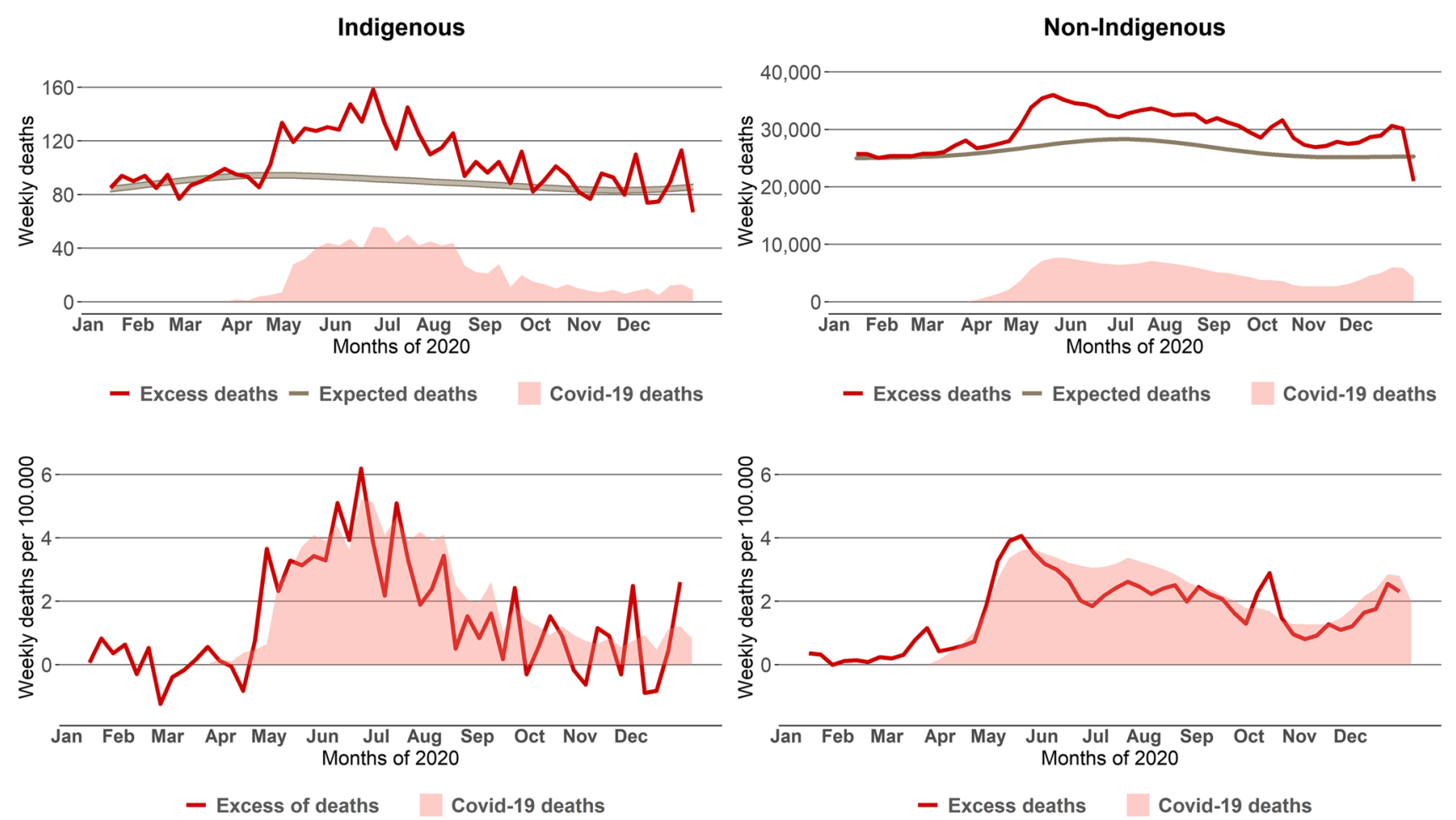

Fig. 4 Comparison of excess deaths and confirmed COVID-19 deaths for Indigenous and non-Indigenous Brazilians in 2020

that imputing missing ethnicity data improves the estimates of ethnic inequalities associated with the impact of COVID-19 [35].
Social gradients in COVID-19 mortality have been documented across several populations, with a greater burden over ethnic minorities and the most socially disadvantaged 
groups [36-38]. In Brazil, the pervasive socioeconomic and health inequalities may be at the root of the disproportionate impact of COVID-19 on Indigenous communities. Raupp et al. (2020) reported that the gap related to basic sanitation infrastructure between Indigenous and non-Indigenous households increased between 2000 and 2010 [39]. Access to clean water and sanitation is critical for preventing the spread of COVID-19 and other infectious diseases, which remain a major cause of mortality among Indigenous Brazilians [40, 41].

Studies reported a disproportionately higher impact of COVID-19 among Indigenous populations from Mexico, Colombia, and among Mayan immigrants living in the USA when compared to their non-Indigenous counterparts [42-45]. Indigenous Ecuadorians experienced a $220 \%$ increase in the expected number of deaths during the pandemic, the highest level of excess deaths among all ethnic groups [46]. In Brazil, a nationwide serological survey conducted in June 2020 observed that Indigenous Brazilians presented a prevalence rate of antibodies against SARS$\mathrm{CoV}-2$ four times the seroprevalence observed among white Brazilians and two times the overall national seroprevalence [17].

Our study demonstrated that a significant increase in excess deaths among Indigenous Brazilians started in early April. This is supported by findings of genomic sequencing of the SARS-CoV-2 revealing that the spread of the virus from metropolitan areas to the rest of the country occurred from March 21 to April 15 [47]. In the South of Brazil, Indigenous communities in the vicinities of large and midsized urban centers were initially more affected by COVID19 [48]. Our findings indicate that the pandemic had a greater impact on Indigenous communities living in rural areas in the South and Southeast only in the last few weeks of 2020. Analysis of 2021 mortality data should examine whether this trend was sustained over a longer period.

Previous research reported that the Indigenous populations living in the North and Center-West regions of Brazil had the highest incidence and mortality rates from COVID19 , which is consistent with our findings [49]. Housing conditions, access to basic sanitation, and nutritional status are considerably worse among Indigenous Peoples from these regions compared to the groups from the South, Southeast, and Northeast [50]. These factors may partially explain the regional differences in excess deaths observed in this study. Moreover, the Indigenous population in the North region is primarily concentrated in Amazonas, a state that faced a health services collapse in April due to the lack of early non-pharmacological interventions such as physical distancing measures [51]. Azevedo et al. (2020) developed an index that quantifies the vulnerability to COVID-19 based on infrastructure and demographic characteristics of Indigenous Lands. The authors observed that the most critical Special
Indigenous Health Districts are concentrated in the North region [52]. It is likely that this extreme scenario contributed to a disproportionate burden of COVID-19 mortality among Indigenous Brazilians in the first wave of the pandemic.

Indigenous Brazilians, especially those living in traditional territories, faced additional barries to accessing healthcare even before the pandemic. As a result of the historical unequal access to health, the Brazilian health system has systematically failed to recognize the distinct health needs of Indigenous communities. These inequalities in accessing healthcare arise from factors such as structural racism, lack of funding to the Indigenous Health Subsystem, geographical distances, lack of transportation, and shortage of health professionals [53, 54]. In 2019, the dismissal of more than 8000 Cuban doctors that primarily served vulnerable and remote communities across all regions of Brazil had a major impact on the delivery of primary health care to Indigenous communities [55]. It is likely that the COVID-19 pandemic exacerbated the existing barriers to accessing healthcare faced by the Indigenous Peoples from Brazil. The majority of the Indigenous population lives in rural and remote areas, where generally there is a lack of health care infrastructure needed to treat severe COVID-19 patients [56]. Although the Indigenous population has been considered a high priority for the COVID-19 vaccination, which may have protected Indigenous Peoples from a more severe second wave of the pandemic in 2021, the exclusion of Indigenous Brazilians living in urban areas from the first vaccination group against COVID-19 may have contributed to increasing inequalities within this population [57].

The hostile political agenda for Indigenous rights in Brazil and the recent weakening of environmental protection policies are likely to have increased the vulnerability of the Indigenous population to the pandemic. Evidence has shown that the incidence of COVID-19 cases among the Indigenous Peoples from the Amazon area is directly correlated with illegal activities in Indigenous territories such as land grabbing, mining, and deforestation [34]. Conflicts between Indigenous populations and invaders may represent an important source of exposure of Indigenous communities to the SARS-CoV-2. Furthermore, the dismantling of regulations and institutions responsible for environmental protection in Brazil, a process intensified by the current federal administration during the pandemic [58], not only harms Indigenous populations and their constitutional rights but increases the likelihood of new zoonotic disease outbreaks $[59,60]$.

These results must be interpreted with caution and a number of limitations should be borne in mind. Although we accounted for demographic changes in the Indigenous population over the last decade, some level of interregional migration may have occurred and influenced estimates of population size. Assessing the excess mortality 
from different causes of death was not feasible due to low statistical power, especially when considering the Indigenous sample. Estimates of excess deaths were not adjusted by age as updated data on the population pyramid structure of Indigenous Brazilians was not available. Our analysis is restricted to the year of 2020 because mortality data related to 2021 has not been disclosed by the Brazilian Mortality Information System. We were not able to assess whether there were differences in excess deaths between rural and urban Indigenous populations due to the unavailability of such granular data. Due to a potential under-reporting of COVID-19 deaths among the Indigenous population, the estimates of excess deaths reported in this study may be conservative, especially regarding the Indigenous population [34]. Consequently, the disparities related to COVID-19 mortality between Indigenous and non-Indigenous Brazilians could be even greater than indicated by our findings.

Indigenous demographic and health statistics in Brazil are characterized by a substantial level of uncertainty [61]. For instance, the data coverage of the Brazilian Information System on Live Births is considerably low in over $10 \%$ of the municipalities of Amazonas, a state that concentrates the highest Indigenous population in Brazil [62]. This "epidemiological invisibility" and lack of quality information may introduce bias to our analysis. Even though the 2020 mortality data may still be subjected to revisions, examining the extent of the impact of COVID19 on Indigenous communities should be a considered a high priority. Despite the low precision of epidemiological information of Indigenous Peoples, the substantial health inequalities between Indigenous and non-Indigenous populations justify the use of these statistics in a cautious and critical analysis.

It is important to bear in mind that the population dynamics of Indigenous Peoples from Brazil are not simply a result of demographic changes, but rather a complex phenomenon affected by historical and socio-political contexts. In other words, individuals may refrain from identifying themselves as "Indigenous" during periods of intense violence and discrimination against Indigenous Peoples. On the other hand, the recognition of Indigenous rights and self-determination may influence individuals of Indigenous background to disclose their ethnic status [63]. Ethnic identity is not a rigid and homogeneous category, but rather a socially constructed reality. We acknowledge that there is important volatility in the skin color classification in Brazil, which may have influenced our findings to some extent [64]. Furthermore, there are methodological differences in terms of how the Brazilian Government estimates the Indigenous population (based on self-declaration) and registers Indigenous deaths (based on interviewer classification, generally a relative).

\section{Conclusion}

Our study provides important insights on the magnitude of disparities in mortality between Indigenous and nonIndigenous Brazilians during an unprecedented scenario of sanitary crisis. The COVID-19 pandemic magnifies the structural inequalities between ethnic groups and places an additional burden on Indigenous populations. In 2020, the proportional increase in excess mortality was substantially higher among Indigenous Brazilians compared to their nonIndigenous counterparts. Findings highlight the urgent need to adopting effective measures that address the increased vulnerability of Indigenous Peoples to COVID-19.

Supplementary Information The online version contains supplementary material available at https://doi.org/10.1007/s40615-021-01162-w.

Author Contribution GHS acquired and analyzed the data and drafted the article. LJ, MGHB, and EMC drafted the article and critically revised the manuscript for intellectual content. All authors have approved the manuscript and agreed with its submission to the journal.

Availability of Data and Material All the data used in this study was obtained from publicly available Government databases.

Code Availability The code used for the analyses is available from the corresponding author (GHS) on request.

\section{Declarations}

Ethics Approval Not applicable.

Consent to Participate Not applicable.

Consent for Publication Not applicable.

Conflict of Interest The authors declare no competing interests.

\section{References}

1. Benzaken AS, Pereira GFM, Costa L, Tanuri A, Santos AF, Soares MA. Antiretroviral treatment, government policy and economy of HIV/AIDS in Brazil: is it time for HIV cure in the country? AIDS Res Ther. 2019;16(1):19.

2. Peiter PC, Pereira RDS, Nunes Moreira MC, Nascimento M, Tavares MFL, Franco VDC, et al. Zika epidemic and microcephaly in Brazil: challenges for access to health care and promotion in three epidemic areas. PLoS One. 2020;15(7):e0235010.

3. Boschiero MN, Palamim CVC, Ortega MM, Mauch RM, Marson FAL. One year of coronavirus disease 2019 (COVID-19) in Brazil: a political and social overview. Ann Glob Health. 2021;87(1):44.

4. Lotta G, Wenham C, Nunes J, Pimenta DN. Community health workers reveal COVID-19 disaster in Brazil. Lancet. 2020;396(10248):365-6.

5. Lasco G. Medical populism and the COVID-19 pandemic. Glob Public Health. 2020;15(10):1417-29. 
6. Fonseca EMD, Nattrass N, Lazaro LLB, Bastos FI. Political discourse, denialism and leadership failure in Brazil's response to COVID-19. Glob Public Health. 2021;16(8-9):1251-66.

7. Ortega F, Orsini M. Governing COVID-19 without government in Brazil: Ignorance, neoliberal authoritarianism, and the collapse of public health leadership. Glob Public Health. 2020;15(9):1257-77.

8. Roser M, Ritchie H, Ortiz-Ospina E, Hasell J. Coronavirus pandemic (COVID-19). 2020. Published online at OurWorldInData. org. Retrieved from: https://ourworldindata.org/coronavirus. Accessed 20 Sept 2021.

9. Biehl J, Prates LEA, Amon JJ. Supreme Court v. Necropolitics: the chaotic judicialization of COVID-19 in Brazil. Health Hum Rights. 2021;23(1):151-62.

10. Ricardo FP, Gongora MF. Enclosures and resistance: isolated Indigenous Peoples in Brazilian Amazonia. Instituto Socioambiental: São Paulo; 2019.

11. Censo Demográfico IBGE. Características Gerais dos Indígenas - Resultados do Universo. Rio de Janeiro: IBGE; 2010. p. 2012.

12. Santos RV, Borges GM, Campos MB, Queiroz BL, Coimbra CEA $\mathrm{Jr}$, Welch JR. Indigenous children and adolescent mortality inequity in Brazil: what can we learn from the 2010 National Demographic Census? SSM Popul Health. 2020;10:100537. https://doi. org/10.1016/j.ssmph.2020.100537.

13. Milanez F, Sá L, Krenak A, Cruz FSM, Ramos EU, Jesus GS. Existence and difference: racism against Indigenous Peoples. Rev Direito Práx. 2019;10(03):2161-81. https://doi.org/10.1590/21798966/2019/43886.

14. Mentona M, Milanez F, Souza JMA, Cruz FSM. The COVID-19 pandemic intensified resource conflicts and indigenous resistance in Brazil. World Dev. 2021;138:105222. https://doi.org/10.1016/j. worlddev.2020.105222.

15. Brazilian Federal Supreme Court. Case law compilation: Covid19. Brasília: STF. 2021. Available at: http://www.stf.jus.br/arqui vo/cms/publicacaoPublicacaoTematica/anexo/case_law_compi lation_covid19_2.pdf. Accessed 18 Jun 2021.

16. Herbetta A, Pocuhto T, Pimentel Da Silva MDS, Guajajara C. Urgent considerations on the relationship between the advance of Covid-19 in indigenous territories in Brazil and the impacts of monoepistemic public policies. Front Sociol. 2021;6:623656.

17. Hallal PC, Hartwig FP, Horta BL, Silveira MF, Struchiner CJ, Vidaletti LP, et al. SARS-CoV-2 antibody prevalence in Brazil: results from two successive nationwide serological household surveys. Lancet Glob Health. 2020;8(11):e1390-8.

18. da Silva LL, Nascimento PE, Araújo OCG, Pereira TMG. The articulation of the Indigenous Peoples of Brazil in facing the covid-19 pandemic. Front Sociol. 2021;6:611336.

19. Articulation of the Indigenous Peoples of Brazil - APIB. Our struggle is for life. Brazil: APIB; 2020. Available at: https://emerg enciaindigena.apiboficial.org/files/2020/12/APIB_relatoriocovid_ v7EN.pdf. Accessed 19 Jun 2021.

20. Socioambiental Instituto. Povos Indígenas no Brasil: 2011/2016. São Paulo: ISA; 2017.

21. Zavaleta-Cortijo C, Ford JD, Arotoma-Rojas I, Lwasa S, Lancha-Rucoba G, García PJ, et al. Climate change and COVID19: reinforcing Indigenous food systems. Lancet Planet Health. 2020;4(9):e381-2.

22. Freitas ARR, Medeiros NM, Frutuoso LCV, Beckedorff OA, Martin LMA, Coelho MMM, et al. Tracking excess deaths associated with the COVID-19 epidemic as an epidemiological surveillance strategy-preliminary results of the evaluation of six Brazilian capitals. Rev Soc Bras Med Trop. 2020;53:e20200558.

23. Ritchie H, Ortiz-Ospina E, Beltekian D, Mathieu E, Hasell J, Macdonald B, et al. Coronavirus pandemic (COVID-19). 2020. Published online at OurWorldInData.org. Retrieved from: https:// ourworldindata.org/coronavirus. Accessed 19 Jun 2021.
24. Acosta RJ, Irizarry RA. Monitoring health systems by estimating excess mortality. medRxiv. 2020;06.06.20120857. https:// doi.org/10.1101/2020.06.06.20120857.

25. Brazil. DATASUS. Sistema de Informações de Mortalidade. Available at: http://www2.datasus.gov.br/DATASUS/index.php? area $=060701$. Acessed on May 20, 2021.

26. GBD 2016 Brazil Collaborators. Burden of disease in Brazil, 1990-2016 a systematic subnational analysis for the Global Burden of Disease Study 2016. Lancet. 2016;392(10149):760-75.

27. Instituto Brasileiro de Geografia e Estatística (IBGE). Cities and states of Brazil. . Available at: https://cidades.ibge.gov.br/. Accessed on May 18, 2021.

28. Brazil. DATASUS. Sistema de Informações sobre Nascidos Vivos. Available at: http://tabnet.datasus.gov.br/cgi/deftohtm. exe?sinasc/cnv/nvuf.def. Accessed on May 20, 2021.

29. Islam N, Shkolnikov VM, Acosta RJ, Klimkin I, Kawachi I, Irizarry RA, et al. Excess deaths associated with covid-19 pandemic in 2020: age and sex disaggregated time series analysis in 29 high income countries. BMJ. 2021;373:n1137.

30. Orellana JDY, Marrero L, Horta BL. Excess deaths from respiratory causes in eight Brazilian metropolises during the first six months of the COVID-19 pandemic. Cad Saude Publica. 2021;37(5):e00328720.

31. Carvalho TA, Boschiero MN, Marson FAL. COVID-19 in Brazil: 150,000 deaths and the Brazilian underreporting. Diagn Microbiol Infect Dis. 2021;99(3):115258.

32. Alves THE, de Souza TA, Silva SA, Ramos NA, de Oliveira SV. Underreporting of death by COVID-19 in Brazil's second most populous state. Front Public Health. 2020;8:578645.

33. Orellana JDY, Cunha GMD, Marrero L, Moreira RI, Leite IDC, Horta BL. Excess deaths during the COVID-19 pandemic: underreporting and regional inequalities in Brazil. Cad Saude Publica. 2021;37(1):e00259120.

34. Fellows M, Paye V, Alencar A, Nicácio M, Castro I, Coelho ME, et al. Under-reporting of COVID-19 cases among indigenous peoples in Brazil: a new expression of old inequalities. Front Psychiatry. 2021;12:638359.

35. Labgold K, Hamid S, Shah S, Gandhi NR, Chamberlain A, Khan $\mathrm{F}$, et al. Measuring the missing: greater racial and ethnic disparities in COVID-19 burden after accounting for missing race/ ethnicity data. Epidemiology. 2021;32(2):157-61.

36. Seligman B, Ferranna M, Bloom DE. Social determinants of mortality from COVID-19: a simulation study using NHANES. PLoS Med. 2021;18(1):e1003490.

37. Li SL, Pereira RHM, Prete CA, Zarebski AE, Emanuel L, Alves PJH, et al. Higher risk of death from COVID-19 in lowincome and non-White populations of São Paulo. Brazil BMJ Glob Health. 2021;6(4):e004959. https://doi.org/10.1136/ bmjgh-2021-004959.

38. Mackey K, Ayers CK, Kondo KK, Saha S, Advani SM, Young $\mathrm{S}$, et al. Racial and ethnic disparities in COVID-19-related infections, hospitalizations, and deaths : a systematic review. Ann Intern Med. 2021;174(3):362-73.

39. Raupp L, Cunha GM, Fávaro TR, Santos RV. Sanitation conditions of indigenous and nonindigenous households in Brazil according the 2000 and 2010 national censuses. Cien Saude Colet. 2020;25(10):3753-63.

40. Donde OO, Atoni E, Muia AW, Yillia PT. COVID-19 pandemic: water, sanitation and hygiene (WASH) as a critical control measure remains a major challenge in low-income countries. Water Res. 2021;191:116793.

41. Lima JFB, Silva RAR, D’Eça Júnior A, Batista RFL, Rolim ILTP. Analysis of the mortality trend in the indigenous population of Brazil, 2000-2016. Public Health. 2020;186:87-94.

42. Ibarra-Nava I, Flores-Rodriguez KG, Ruiz-Herrera V, OchoaBayona HC, Salinas-Zertuche A, Padilla-Orozco M, et al. Ethnic 
disparities in COVID-19 mortality in Mexico: a cross-sectional study based on national data. PLoS One. 2021;16(3):e0239168.

43. Argoty-Pantoja AD, Robles-Rivera K, Rivera-Paredez B, Salmerón J. COVID-19 fatality in Mexico's indigenous populations. Public Health. 2021;193:69-75.

44. Cifuentes MP, Rodriguez-Villamizar LA, Rojas-Botero ML, Alvarez-Moreno CA, Fernández-Niño JA. Socioeconomic inequalities associated with mortality for COVID-19 in Colombia: a cohort nationwide study. J Epidemiol Community Health. 2021;jech-2020-216275.

45. Foo PK, Perez B, Gupta N, Lorenzo GJ, Misa NY, Gutierrez BS, et al. High rates of COVID-19 infection among Indigenous Maya at a US Safety-Net Health System in California. Public Health Rep. 2021;136(3):295-300.

46. Cuéllar L, Torres I, Romero-Severson E, Mahesh R, Ortega N, Pungitore $\mathrm{S}$, et al. Excess deaths reveal the true spatial, temporal, and demographic impact of COVID-19 on mortality in Ecuador. Int J Epidemiol. 2021;dyab163. https://doi.org/10.1093/ije/dyab1 63.

47. Candido DS, Claro IM, de Jesus JG, Souza WM, Moreira FRR, Dellicour S, et al. Evolution and epidemic spread of SARS-CoV-2 in Brazil. Science. 2020;369(6508):1255-60.

48. Polidoro M, de Assis Mendonça F, Meneghel SN, Alves-Brito A, Gonçalves M, Bairros F, et al. Territories under siege: risks of the decimation of Indigenous and Quilombolas Peoples in the context of COVID-19 in South Brazil. J Racial Ethn Health Disparities. 2020;8(5):1119-29. https://doi.org/10.1007/s40615-020-00868-7.

49. Santos VS, Souza Araújo AA, de Oliveira JR, Quintans-Júnior LJ, Martins-Filho PR. COVID-19 mortality among Indigenous people in Brazil: a nationwide register-based study. J Public Health (Oxf). 2021;43(2):e250-1.

50. Coimbra CE, Santos RV, Welch JR, Cardoso AM, de Souza MC, Garnelo L, et al. The First National Survey of Indigenous People's Health and Nutrition in Brazil: rationale, methodology, and overview of results. BMC Public Health. 2013;13:52.

51. Ferrante L, Steinmetz WA, Almeida ACL, Leão J, Vassão RC, Tupinambás U, et al. Brazil's policies condemn Amazonia to a second wave of COVID-19. Nat Med. 2020;26(9):1315.

52. Azevedo MM, Damasco F, Antunes M, Martins MH, Rebouças MP. Analysis of the demographic and infrastructural vulnerability of Indigenous Lands to Covid-19. São Paulo: Instituto Socioambiental; 2020.

53. Malacarne J, Gava C, Escobar AL, Souza-Santos R, Basta PC. Health service access for tuberculosis diagnosis and treatment among indigenous peoples in Rondônia state, Brazilian Amazon, 2009-2011: a cross-sectional study. Epidemiol Serv Saude. 2019;28(3):e2018231.

54. Flores-Ramírez R, Berumen-Rodríguez AA, Martínez-Castillo MA, Alcántara-Quintana LE, Díaz-Barriga F, Díaz de
León-Martínez L. A review of Environmental risks and vulnerability factors of indigenous populations from Latin America and the Caribbean in the face of the COVID-19. Glob Public Health. 2021;16(7):975-99.

55. Francesconi GV, Tasca R, Basu S, Rocha TAH, Rasella D. Mortality associated with alternative policy options for primary care and the Mais Médicos (More Doctors) Program in Brazil: forecasting future scenarios. Rev Panam Salud Publica. 2020;44:e31.

56. Bezerra É, Santos PSD, Lisbinski FC, Dias LC. Spatial analysis of Brazil's COVID-19 response capacity: a proposal for a Healthcare Infrastructure Index. Cien Saude Colet. 2020;25(12):4957-67.

57. Dos Santos Costa AC, Ahmad S, Essar MY. Vaccination: Brazil fails Indigenous people again with two-tier scheme. Nature. 2021;593(7860):510. https://doi.org/10.1038/ d41586-021-01409-w.

58. Vale MM, Berenguer E, Argollo de Menezes M, Viveiros de Castro EB, Pugliese de Siqueira L, Portela RCQ. The COVID-19 pandemic as an opportunity to weaken environmental protection in Brazil. Biol Conserv. 2021;255:108994.

59. Ellwanger JH, Kulmann-Leal B, Kaminski VL, ValverdeVillegas JM, Veiga ABGD, Spilki FR, et al. Beyond diversity loss and climate change: impacts of Amazon deforestation on infectious diseases and public health. An Acad Bras Cienc. 2020;92(1):e20191375.

60. Lorenz C, de Oliveira Lage M, Chiaravalloti-Neto F. Deforestation hotspots, climate crisis, and the perfect scenario for the next epidemic: the Amazon time bomb. Sci Total Environ. 2021;783:147090.

61. Coimbra CEAJ, Santos RV. Health, minorities and inequality: some webs of inter-relations, emphasizing indigenous peoples in Brazil. Cienc Saude Colet. 2000;5(1):125-32. Portuguese.

62. Szwarcwald CL, Leal MDC, Esteves-Pereira AP, Almeida WDS, Frias PG, et al. Evaluation of data from the Brazilian Information System on Live Births (SINASC). Cad Saude Publica. 2019;35(10):e00214918. Portuguese.

63. Perz S, Warren J, Kennedy D. Contributions of racial-ethnic reclassification and demographic processes to Indigenous population resurgence: the case of Brazil. Lat Am Res Rev. 2008;43(2):7-33.

64. Muniz JO, Bastos JL. Classificatory volatility and (in)consistency of racial inequality. Cad Saude Publica. 2017;33(Suppl 1):e00082816.

Publisher's Note Springer Nature remains neutral with regard to jurisdictional claims in published maps and institutional affiliations. 